\title{
Reflective Thinking: An Analysis of Students' Reflections in Their Learning about Computers in Education
}

\author{
Fariza Khalid1, Mazalah Ahmad', Aidah Abdul Karim1, Md. Yusoff Daud1, Rosseni Din² \\ ${ }^{1}$ Department of Teaching \& Learning Innovations, Faculty of Education, National University of Malaysia, Bangi, \\ Malaysia \\ ${ }^{2}$ Personalized Learning Research Group, Department of Community Education and Wellness, Faculty of \\ Education, National University of Malaysia, Bangi, Malaysia \\ Email: fariza.khalid@ukm.edu.my, mdyusoffdaud@ukm.edu.my, eda@ukm.edu.my, mazalah@ukm.edu.my, \\ rosseni@ukm.edu.my
}

Received 9 September 2015; accepted 21 November 2015; published 24 November 2015

Copyright (C) 2015 by authors and Scientific Research Publishing Inc.

This work is licensed under the Creative Commons Attribution International License (CC BY). http://creativecommons.org/licenses/by/4.0/

(c) (7) Open Access

\section{Abstract}

This study aims to examine reflective capacity among students when learning about computers in education. The study involved 35 e-portfolios written by first-year students who enrolled on the Computers in Education course in the Faculty of Education, Universiti Kebangsaan Malaysia. All the students taking this course were required to publish "reflections" based on their weekly learning activities via individual e-portfolios. Thematic analysis was done using Nvivo 10 software to categorize the content of the students' reflections. The analysis reveals that a large percentage of the "reflections" were non-reflective rather than reflective actions. This finding has implications for the way the course is designed, requiring a supportive environment, mentoring and group discussions, as reflective thinking is not spontaneous, but should be deliberately stimulated by the educational context.

\section{Keywords}

Reflective Thinking, Learning, Computer Education, Analysis, University, E-Portfolio, Journal

\section{Introduction}

With the rapid development of technology for education in the twenty-first century, learners have become more exposed to various sources of knowledge. The availability of thousands of websites and learning materials may spur learning in more meaningful ways. In line with this progression, learners are now expected to become more 
independent, reflective learners. Teachers are no longer solely information providers; rather, the role of teachers is to facilitate learners' learning. Thus, it is essential that today's learners acquire the capacity to engage in reflective practices, as having such skills will help them to become effective in their professional contexts (Thorpe, 2004).

The ability to reflect on one's learning and to learn from reflecting on experience is a fundamental skill for learning and improvement. Reflective thinking involves higher-order thinking skills and therefore requires deep thinking and the ability to rationalize every decision made. In the Faculty of Education, The National University of Malaysia, one of the subjects that are compulsory for all first year students is Computers in Education (GE1155). This course aims to prepare pre-service teachers with knowledge and skills related to using computers for teaching and learning, research, and management; i.e. it is related to using computers as a "tool", "tutor" and "tutee". This course also introduces issues related to twenty-first century skills, Web 2.0, Microsoft Office, OpenOffice.org and other open source software, and the use of social media as a learning platform. The topics offered on the course require students not only to practice new skills, but also to create meaning and construct their own conclusions based on their learning-by-doing experiences regarding all the related topics. In addition, collaborative work is an essential part of the learning activities, which is called the "Think, Pair and Share" process. This strategy is designed to differentiate instruction by providing students with the time and structure to think about a given topic, enabling them to formulate individual ideas and share these ideas with a peer. This learning strategy promotes classroom participation by encouraging a high degree of pupil response, rather than using a basic recitation method in which a teacher poses a question and one student offers a response. Therefore, learning on this course requires students to be able to share, and to reflect on their learning activities.

For this purpose, all students taking this course are required to develop an e-portfolio using Weebly. An e-portfolio is a digitized version of a portfolio, which consists of the resources and accomplishments of a student. This collection can include materials in the form of texts, graphics or multimedia, and can be archived on a CD-ROM or on a website (Awwad, Nofal, \& Salti, 2013). E-portfolios have an impact on educational practice that can be used to document learning in progress, as well as its culmination (Henderson, Napan, \& Monteiro, 2004). Through the use of e-portfolios, students are able to develop their thinking skills and engage themselves in collaborative work and interactions about their learning (Bell et al., 2011; Zeichner \& Wray, 2001). The benefit of e-portfolios is that students are able to access others' e-portfolios available online, to see examples of others' work and to have discussions about their tasks. Another important element of e-portfolios is students' reflections and self-evaluations (Lankes, 1995). Thus, an e-portfolio is not merely a compilation of students' work, but it also helps students to gain value from the process of continuous self-assessment and reflection, which involves higher-order thinking skills, and reflects students' progress, strength and creativity, as well as their capability to apply a concept or piece of knowledge they have gained through their course to their tasks (Awwad, Nofal, \& Salti, 2013). Therefore, reflective thinking is a key component to support deep learning. That is why e-portfolios provide the necessary conditions for cultivating thinking among students (Chung, Leong, \& Loo, 2006).

As well as sharing their assignments using their e-portfolios, all students are required to write weekly reflections, indicating their feelings, emotions, critiques and conclusions related to their learning experiences. These reflections are published in their e-portfolios. An example of a student's reflection is shown in Figure 1.

\section{Reflective Thinking}

There are many definitions of reflective thinking. For example, Boud, Keogh and Walker (1985: p. 18) state that "reflection in the context of learning is a generic term for those intellectual and affective activities in which individuals engage to explore their experiences in order to lead to new understanding and appreciations”. Boud (1999) then asserts that the emergence of reflective practice is part of a change that "acknowledge[s] the need for students to act and think professionally as an integral part of learning throughout courses of study, rather than insisting that students must learn the theory before they can engage in practice". These definitions put an emphasis on purposeful critical analysis of knowledge and experience, in order to achieve meaningful learning. Reflective learning therefore relates to learners exploring their understanding of their actions, processes and experiences, as well as the impact of these on themselves and others (Mann, Gordon, \& MacLeod, 2009). However, it is also vital to note that in order for students to develop reflective capacity, they should be exposed to learning experiences that equip them with the ability to engage in reflective practices (Schon, 1987). 


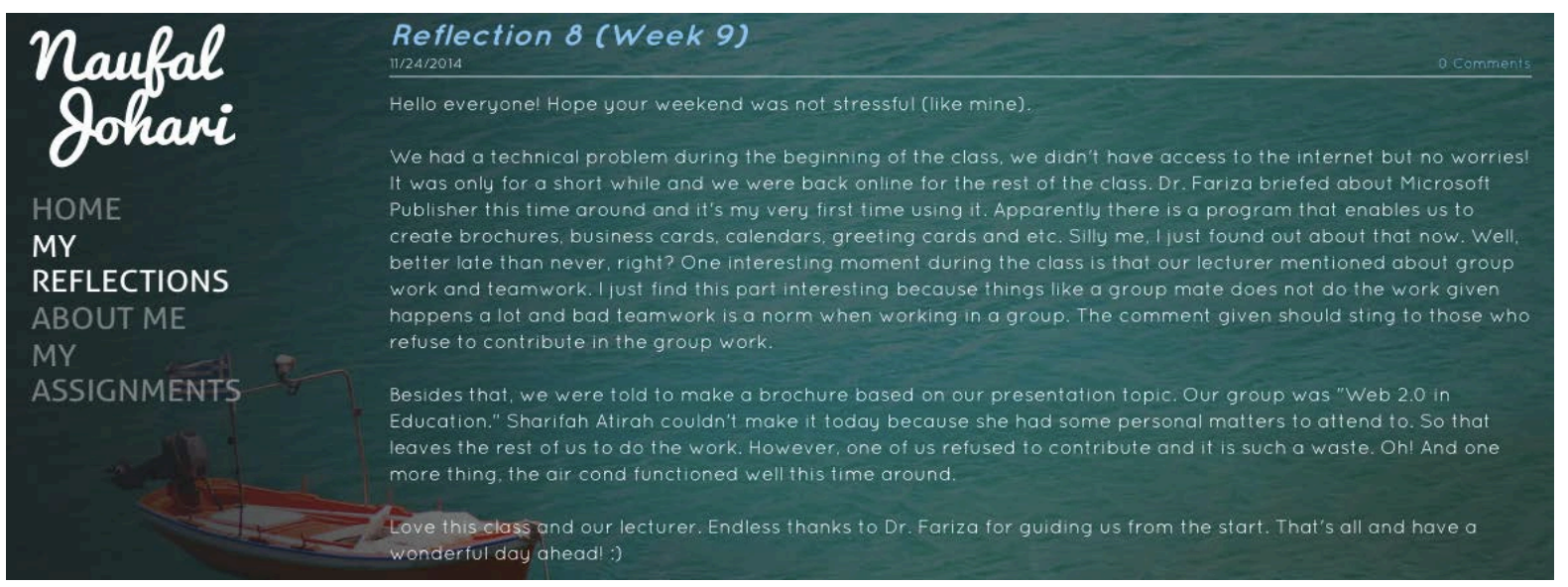

Figure 1. An example of a student's reflection in an e-portfolio.

According to Baxter (1992: p. 384), what is meant by "habitual action" is "that which has been learnt before and through frequent use becomes an activity that is performed automatically or with little conscious thought". In the context of learning on the GE1155 course, it is anticipated that students will learn and be able to apply some knowledge in the production of their personal e-portfolios using Weebly. In time, this may become habitual or "taken-for-granted" (Lucas, 2011). As students become more used to the creation of entries and uploading material to their e-portfolios or writing their reflections, tasks that initially seemed ill-structured become seen as well-structured, and students do not have to think too much in completing their weekly routine tasks. Awwad, Nofal and Salti (2013) describe habitual action by giving an example of using a keyboard or riding a bicycle. Once a person is used to keyboards or bicycles, the tasks can easily be done. However, habitual action may differ from one student to another, as it will be determined by the extent to which they are accustomed to performing a task.

The next category is "understanding", which Kember et al. (2000: p. 384) describe as "thoughtful action" that "makes use of existing knowledge, without attempting to appraise that knowledge, so learning remains within pre-existing meaning schemes and perspectives. Thoughtful action can be described as a cognitive process". They also posit that "thoughtful action" or "understanding" is the best description of the phase of learning that takes place in universities. To them, Bloom's taxonomy's perspective on learning, which covers knowledge, comprehension, application, analysis and synthesis, would generally be placed in Mezirow's category of "thoughtful action". For example, on the GE1155 course, the use of Excel, in addition to being used for managing marks in a classroom context, could be adopted by students to manage their monthly expenditure, or the use of Weebly could be adopted for creating a business website.

"Reflection" involves the "critique of assumptions about the content or process of problem solving. The critique of premises or presuppositions pertains to problem posing as distinct from problem solving. Problem posing involves making a taken-for-granted situation problematic, raising questions regarding its validity.” (Kember et al., 2000: p. 384). For example, on the GE1155 course, students might reflect on the applicability of certain video creation techniques.

The last category is "critical reflection", which involves the critique of assumptions (Lucas, 2011). Mezirow (1991: p. 223) describes this as "transformative learning", which involves the transformation of the beliefs, opinions, attitudes and emotional reactions that constitute students' meaning scheme. Lucas (2011: p. 6) further explains this as involving reflection on presuppositions or "the assessment of assumptions implicit in beliefs, including beliefs about how to solve problems". For example, students on the GE1155 course might undergo a realization that there are certain tricks or techniques that should be used in a particular context instead of their previous practice. In addition, by reading others' reflections, students will gather certain ideas about how to create better reflections, which transform their current understanding of what reflection means. They may then realize that writing reflections is not solely done for the sake of writing, but it challenges their critical and reflective thinking: as Kember et al. (2000: p. 385) explain, "critical reflection" involves "becoming aware of why we perceive, think, feel or act as we do".

On the GE1155 course, the aims are to expose students to learning experiences that equip them with reflective 
practices, so that they will be able to develop their reflective capacity (Schon, 1987). Through the process of writing their weekly reflections, it is hoped that students will gradually develop their reflective capacity, by not only reflecting on their own work, but also on others', so as to help them identify the problem raised and how to solve it appropriately. As a consequence, it is vital to assess their reflections, as only by doing the analysis will we know their reflective capacity and what else needs to be done for the next cohort of students taking this course to optimize their capability to be reflective learners. This research was conducted with the aim of examining students' reflective capacity as shown in their reflective writings in their e-portfolios.

\section{Methodology}

There are a total of 151 students from three programs (Special Education [SE], Sports and Recreation [SR] and Teaching English as a Second Language [TESL]) taking the Computer in Education course. These students are divided into seven tutorial groups led by four lecturers. For the purposes of this study, five e-portfolios from each group were selected randomly (see Figure 2). Each e-portfolio contained 14 reflections, which had been written every week of the semester (there are 14 weeks in the semester), and this makes the total number of analyzed reflections to be 490 .

To do the analysis, all the reflections were transferred to Nvivo 10 as files based on individuals' names (for the purposes of this report, pseudonyms are used). Reading through each individual's reflections, I then coded the answers according to suitable or appropriate codes. The goal of coding is to come up with a set of categories that provide a reasonable reconstruction of the data that have been collected (Lincoln \& Guba, 1985). In naming the codes, I referred to answers from the written reflections, looking for the words or terms used, or creating the names on my own to reflect the meaning of the key points of certain sentences. I also referred to Kember et al.'s (2000) categories of reflection in naming the codes or categories emerging from the analysis. After the coding had been done, the next task was to categorize the codes into categories. Categories are "umbrellas" (Denscombe, 2010: p. 285) that consist of a number of codes, and these categories reflect the general idea of classifying the various components of the data under key headings.

\section{Result and Discussion}

Based on the thematic analysis done, as shown in Table 1, six main themes emerged: 1) What they did; 2) feelings about the course or activities; 3) statements of knowledge, comparison and conclusion; 4) reflections on their process and others'; 5) what they need to improve; and 6) Changes in perspective. As indicated in Table 1,

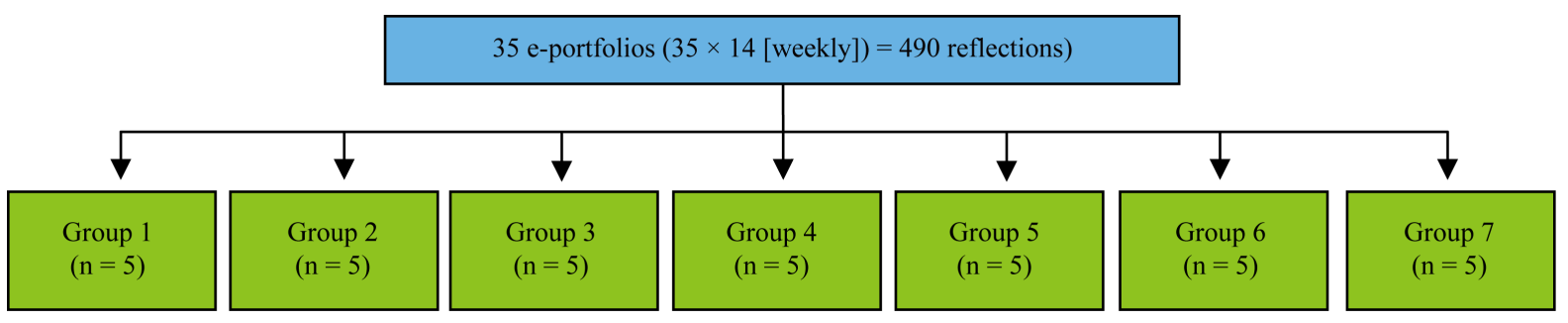

Figure 2. The number of e-portfolios and reflections analyzed in the study.

Table 1. The themes and the number of references and sources emerging from the analysis.

\begin{tabular}{ccc} 
Themes & Source & References \\
\hline What they did & 21 & 66 \\
Feelings about the course or activities & 34 & 70 \\
Statement of knowledge, comparison \& conclusion & 32 & 70 \\
Reflections on their process and others' & 22 & 42 \\
What they need to improve & 25 & 31 \\
Changes in perspective & 26 & 38 \\
\hline
\end{tabular}

Legend: Source — number of participants citing the theme; References—number of evidences/answers. 
the category of "Feelings about the course or activities" showed the highest citation, i.e. 34 sources (97.17\%) with 70 references (22.08\%), followed by "statements of knowledge, comparison and conclusion” coming from 32 sources (91.42\%) with 70 references (22.08\%). The category of "what they did" was cited by 21 sources $(60.00 \%)$ with a total of 66 references $(20.82 \%)$. The lowest number can be seen in the category of "what they need to improve”, cited by 25 sources (71.42\%) with 31 references (8.22\%).

\subsection{What They Did}

This category refers to descriptions or stories about what the students did or what was explained to them in class. For example, one student explained what they were told to do and what they did in order to complete the task:

"As the class begins, our beloved lecturer never wastes any time, because she will immediately start the class. We were told to find materials on our assignment as we had to also do a presentation on it. We started looking for related materials via Google Scholar and shared the materials with other members of the group via Google Drive.” (Sarah)

Another student wrote:

“In this week's class, as usual, there was a presentation by one of the groups in our class. This week's presentation was carried out by Group 4 who talked about Mobile Learning. It was full of information about what mobile learning is and how to use it effectively in education." (Deena)

According to Kember et al. (2000), “habitual action” and "understanding” are not considered reflective in meaning, as in "habitual action", a person only does actions that are routinely done without having to think about doing them. Similarly, as seen from the analysis in this category, no such reflective activities were involved as students were just describing what they had actually done in class.

\subsection{Feelings about the Course or Activities}

This category showed the highest number of citations, coming from $97.17 \%$ (34 of 35) students whose e-portfolios were selected for this study. In this category, students expressed their feelings and emotions related to the course in general or to the specific activity they did in a certain week of class. In this category, various feelings were revealed: sadness, excitement, anger, anxiety, feeling lost, thankfulness, satisfaction, and happiness. Some of the examples of the students' feelings about the course in general are as follows:

Thankfulness:

"All I want to say is I have never experience such a wonderful journey as I had in the Computers in Education Class. I really am thankful to be blessed and getting an opportunity to study in UKM and broaden my knowledge here.” (Veen)

Excitement:

"But I was excited to learn something new again from Dr. Fariza. Wohoooo!!! There is no class like hers. It's among the best because I get to learn a lot of applications in the one and only Computers in Education class" (Ben)

Pressure:

“But the fact was more painful as our assignments were increasing... huhuhu... horrible feeling!!” (Ann)

Others chose to share their feelings about certain activities, for example:

Happiness/satisfaction:

"This week was the last class for this semester, literally as it was held on Friday at night. I dare say it was the best of all the classes that we had for Computers in Education.” (Fiona)

Sadness:

"Lastly, after the presentation we had a photo session with Dr. Fariza. It was a very meaningful moment for me. It was a very thorny, bumpy and difficult journey for me for when facing this semester." (Zeeta) 
Pride:

"But I succeed in finishing this course with pride. I am glad to be able to work with my teammates. Ah! Feeling proud!” (Fikri)

\subsection{Statements of Knowledge, Comparison and Conclusion}

The next category emerging from the analysis was statements of the fact that they had learned something (knowledge), statements comparing things (comparison) and statements making conclusions based on the activities they had undertaken in the week. This category was cited by $91.42 \%$ (32 out of 35 respondents), with 70 references. Knowledge or thoughtful action, as explained by Kember et al. (2000), is related to a cognitive process in which learning takes place. Knowledge of thoughtful action also relates closely to elements of Bloom's Taxonomy such as knowledge, comprehension, application, analysis and synthesis. When a student describes knowledge that they have obtained, makes comparisons or draws conclusions based on what activities they have done, all these references fall under this category. An example of a student indicating their knowledge:

"I also learnt the ethics of sending proper e-mails. A signature should be added in every e-mail to make it easier for the receiver to identify the sender's basic information. Even in the virtual world, we have to respect each other thus; we can lessen cyber-crime or at least avoid it." (Mukhriz)

Example of a student sharing their thoughts in comparing things:

"I figured out that LMS functions more to report the purposes and help in the learning strategy to improve student's performances while CMS is narrower and specific in scope because it focuses more on the distribution and management of e-learning and instructor-led courses. I think CMS needs to be available all the time to enable students to use it much like i-folio UKM." (Azril)

Some of the students also indicated the conclusions they had made based on new findings they obtained through the activities in the computer lab. An example of this:

"I guess I understand the reason behind the rules. This is to make sure that the slideshows are easy to understand but still interesting to the viewers. Now I know the importance of this concept which is we should be applying it for our presentation for the topic on open source software (OSS) and learning ICT." (Rudy)

\subsection{Reflections on Their Process and Others'}

This category refers to critiques or reflections on the process they underwent related to certain activities, or could also involve them criticizing others' process or work, and through the reflection thinking of doing something to improve their own current practice or process. For example, some of the students revealed having problems during one of their assignments. They could not save their movie file onto the laptop after creating it using one of the movie maker applications available on the Internet. One student wrote about how they finally solved their problem and was happy that everything went well after all the hurdles:

"The hardest thing I ever faced in completing the task was regarding the multimedia video. One of the videos that my group mate and I created could not be downloaded for some unknown reason. We were panicked as tonight would be the presentation session. We had no option but to do it all over again using Powtoon. We had to sit together for more than 3 hours. Nobody wanted to have a break. That was a really amazing experience. I am so glad that we managed to present our video at last. I think what I learned from this is actually... it reminds me not to be too ambitious as we were so eager to use more than four applications to be combined in a single movie." (Ika)

Students also wrote about their reflections on others' work. For example, one of the students reflected on work done by students from a different program:

"As I went through the other students from sport and special education, I realized there is an obvious difference between their answers and TESL students' answers. I was scrolling down through all the answers and found out that TESL students tend to answer in a straight and formal way to every question asked. Meanwhile, sport and special education students answered in very dramatic and poetic sentences. I was 
very amused though with that. Perhaps TESL students are either very stiff and serious or lazy to the core of our bones. Other than that, this week every group was assigned with a respective topic regarding the latest issues in technology." (Osin)

\subsection{What They Need to Improve}

As well as reflecting on their processes and others', 25 students (71.42\%) wrote about things that they needed to improve. This category showed 31 references. For example, one of the students pinpointed that she would like to improve on her time management so that she would be able to complete her tasks on time and would not bother her group members:

"From this experience I can conclude that my time management is very bad. I need to manage my time well after this in order to be fair to my teammates.” (Lynn)

Another student cited that she was not comfortable with her lack of confidence in talking in front of the class and that made her determined to enhance her public speaking skills. The answer can be seen below

"Ermm... Then, I just go with the flow. Presenting, although I know no one of my friends understands what I'm saying that time. Hmm... Sad for a teacher-to-be. I need to polish my speaking and general speaking. I have to. So that I won't be that shaky girl anymore.” (Baiti)

\subsection{Changes in Perspective}

This category relates to what Kember et al. (2000) describe as “critical reflection”, or what Mezirow calls "transformative learning”. To achieve this, a transformation in terms of one's beliefs, opinions or attitudes towards a certain thing is revealed in the reflection writing. By undergoing experiences and doing certain activities, students obtained some new ideas or conceptions, which then changed their perspectives or notions about something. Some of their writings show that the students were even aware of why they perceived, thought or did things the way they did. For example:

"Attending this course made me rethink what I can do with my computer. It is no longer for typing in Word only. There are so many things to explore! As the same time, computers have changed my lifestyle where now I can do a lot of art design by using applications on the computer which gives a better effect and results of my painting and there are varieties of entertainment where I can get through when I switch on my computer and connect to the Internet. Computers are not the most important things in this world, nor are they the least important either." (Chin)

According to Kember et al. (2000), "habitual action” and "understanding” are not considered reflective in meaning, as in "habitual action", a person only does actions that are routinely done without having to think about doing them. Similarly, as emerged from the analysis under the category of "what they did", where no such reflective activities were involved as in students were just describing what they actually did in the class. Students also frequently wrote about their feelings about the course or the activities they were involved in every week. Kember et al. (1999) see this as part of the affective domain, which refers to feelings or thoughts about something. However, this is counted as non-reflective, as the students were only expressing what they felt.

In addition to the previous two categories ("what they did" and "feelings about the course or activities"), another category that emerged was "statements of knowledge, comparison and conclusion”. This category consisted of some elements of Bloom's Taxonomy, i.e. knowledge, comprehension, and synthesis (conclusion), and this category fits the "understanding” or "thoughtful action” category of Kember et al. (2000). Like the category of "feelings about the course or activities", this category comprises the most references in the students' reflections. However, this is also considered a non-reflective action (Kember et al., 2000).

The next three categories ("reflection on their process and others"”, "what they need to improve" and "changes in their perspective”) are categorized under what Kember et al. (2000) call "reflective actions". Reflections involve the ability of a learner to reflect on what he or she did and in what ways they could improve, or how he or she could overcome the problems he or she faced during activities. This process involved students' capacity to be reflective, as well as being aware of their strengths and weaknesses and at the same time challenging themselves to find solutions to their shortcomings or to improve. As indicated in Table 2, therefore, the 
Table 2. Classification of the categories into reflective and non-reflective actions.

\begin{tabular}{|c|c|c|c|}
\hline Themes & Source & References & Categories \\
\hline What they did & 21 & 66 & \multirow{3}{*}{$\begin{array}{l}\text { Non-reflective } \\
\text { actions } 206 \\
\text { references } \\
(64.98 \%)\end{array}$} \\
\hline Feelings about the course or activities & 34 & 70 & \\
\hline Statement of knowledge, comparison \& conclusion & 32 & 70 & \\
\hline Reflections on their process and others' & 22 & 42 & \multirow{3}{*}{$\begin{array}{c}\text { Reflective actoins } \\
111 \text { references } \\
(35.02 \%)\end{array}$} \\
\hline What they need to improve & 25 & 31 & \\
\hline Changes in perspective & 26 & 38 & \\
\hline
\end{tabular}

Legend: Source—number of participants citing the theme; References—number of evidences/answers.

first three categories ("changes in perspective", "what they need to improve” and "reflections on their process and others"”) are considered reflective actions, while the other three categories ("statements of knowledge, comparison and conclusion", "feelings about the course or activities", and "what they did”) are considered non-reflective actions, which indirectly means that even though students thought that they had written reflections in their individual e-portfolios, they might not have been aware that what they wrote did not represent actual "reflection".

Based on the numbers and percentages of the sources and references for each category, it can be concluded that a large percentage of the reflections was non-reflective (64.98\%), compared to reflective actions (35.02\%). Although the percentage of reflective actions is smaller than that of non-reflective actions, this practice has given insights for these first year students on how they feel and how they could learn more effectively.

\section{Conclusions}

The main objective of the reflective writing was to inspire students to familiarize themselves with reflective thinking on their learning processes and to identify the processes they could undertake to extend their understanding where gaps were identified. These findings have helped me as a coordinator of this course to find other creative and constructive ways to help cultivate reflective capacity among the students, and to instill awareness of how important it is to be a reflective learner in enhancing learning, particularly when it is related to the creative application of computers for education. These findings also suggest that more intensive training should be provided to the students on producing reflective writing, as well as to strengthen their understanding on the meaning of reflective actions. This is because reflective thinking is not spontaneous; rather, it should be deliberately stimulated by the educational context (Mann, Gordon, \& Macleod, 2009).

Furthermore, there is evidence that undertaking this analysis is important and beneficial for lecturers or teachers to identify students' reflective capacity. The lack of reflective capacity shows us where to start with improvement. I found that the coding scheme of Kember et al. (1999), with refinements, could be used to analyze and categorize types of writing in students' reflections. Overall, reflection writing seems to have helped students to become aware of what they had learned, and what they wanted to learn or improve (Celentin, 2007). It is hoped that reflective thinking, as promoted through this activity, will lead to the construction of better knowledge and skills among the students. In addition, lecturers play an important role in guiding students to develop better reflective capacity through "reflection on their reflections". Perhaps doing reflecting orally on their reflection in class among peers and lecturers will build up students' awareness of what is considered to be actual reflective thinking, as to develop the required skills it is necessary to have a supportive environment, mentoring and group discussions (Mann, Gordon, \& Macleod, 2009).

\section{Acknowledgements}

This study was conducted under the PTS-2014-009 grant.

\section{References}

Awwad, F. M., Nofal, M. B., \& Salti, N. S. (2013). The Impact of Electronic Portfolio on Developing Reflective Thinking and Self-Directed Learning Readiness. Cypriot Journal of Educational Sciences, 8, 78-104. 
Baxter, M. (1992). Knowing and Reasoning in College: Gender Related Patterns in Students' Intellectual Development. San Francisco, CA: Josse-Bass.

Bell, A., Kelton, J., McDonagh, N., Mladenovis, R., \& Morrison, K. (2011). A Critical Evaluation of the Usefulness of a Coding Scheme to Categorise Levels of Reflective Thinking. Assessment \& Evaluation in Higher Education, 36, 797-815. http://dx.doi.org/10.1080/02602938.2010.488795

Boud, D. (1999). Avoiding the Traps: Seeking Good Practice in the Use of Self-Assessment and Reflection in Professional Courses. Social Work Education, 18, 121-132. http://dx.doi.org/10.1080/02615479911220131

Boud, D., Keogh, R., \& Walker, D. (1985). Reflection: Turning Experience into Learning. London: Kogan Page.

Celentin, P. (2007). Online Education: Analysis of Interaction and Knowledge Building Patterns among Foreign Language Teachers. Journal of Distance Education, 21, 39-58.

Chung, T., Leong, M., \& Loo, J. (2006). Automated Mentoring for Reflection in an E-Portfolio. Frontiers in Artificial Intelligence and Applications, 151, 457-464.

Denscombe, M. (2010). The Good Research Guide for Small Scale Research Projects (4th ed.). Buckingham: Open University Press.

Henderson, L., Napan, K., \& Monteiro, S. (2004). Encouraging Reflective Learning: An Online Challenge. Proceedings of the 21st ASCILITE Conference, 5-8 December, Perth.

Kember, D., Leung, D., Jones, A., \& Loke, A. Y. (2000). Development of a Questionnaire to Measure the Level of Reflective Thinking. Assessment \& Evaluation in Higher Education, 25, 381-395. http://dx.doi.org/10.1080/713611442

Kember, D., Jones, A., Loke, A. Y., McKay, J., Sinclair, K., Tse, H., Webb, C., Wong, F., Wong, M., \& Yeung, E. (1999). Determining the Level of Reflective Thinking from Students' Written Journals Using a Coding Scheme Based on the Work of Mezirow. International Journal of Lifelong Education, 18, 18-30. http://dx.doi.org/10.1080/026013799293928

Lankes, A. (1995). Electronic E-Portfolios: A New Idea in Assessment. Eric Digest. ERIC Clearinghouse on Information and Technology, Syracuse, NY: Syracuse University.

Lincoln, Y. S., \& Guba, E. G. (1985). Naturalistic Enquiry. Beverly Hills. CA: Cage.

Lucas, U. (2011). Reflection: What Is Its Role in "Learning to Be a Professional”? Paper Presented at Brunel Business School, 30th November 2011.

http://www.brunel.ac.uk/_data/assets/pdf_file/0020/145154/aarcReflectionWhatIsItsRoleIn.pdf

Mann, K., Gordon, J., \& Macleod, A. (2009). Reflection and Reflective Practice in Health Professions Education: A Systematic Review. Advance in Health Science Education, 14, 595-621. http://dx.doi.org/10.1007/s10459-007-9090-2

Mezirow, J. (1991). Transformative Dimensions of Adult Learning. San Francisco: Jossey-Bass.

Schon, D. (1987). The Reflective Practitioner. London: Temple Smith.

Thorpe, K. (2004). Reflective Learning Journals: From Concept to Practice. Reflective Practice, 5, 328-343. http://dx.doi.org/10.1080/1462394042000270655

Zeichner, K., \& Wray, S. (2001). The Teaching Portfolio in US Teacher Education Programs: What We Know and What We Need to Know. Teaching and teacher Education, 17, 613-621. http://dx.doi.org/10.1016/S0742-051X(01)00017-8 